\title{
COMPORTAMENTO E DISTRIBUIÇÃO DO GASTO PÚBLICO EM AGRICULTURA EM MINAS GERAIS: MULTIFUNCIONALIDADE OU FRAGMENTAÇÃO?
}

\author{
Maria Amarante Pastor Baracho ${ }^{1}$ \\ José Maria Alves da Silva ${ }^{2}$
}

\begin{abstract}
Resumo - Este artigo tem o principal objetivo de identificar o comportamento dos gastos públicos em agricultura no estado de Minas Gerais, no período de 1985 a 2001. Constatou-se tendência à diminuição do volume desses gastos e à pulverização institucional destes, o que indica progressivo esvaziamento de tradicionais atribuições do Estado de apoio e fomento ao setor agrícola, acompanhado de crescente superposição de competências para gastar a verba pública alocada na função agricultura e de sua conseqüente diluição entre distintos sistemas operacionais da administração pública. Se o padrão de distribuição do gasto público em agricultura em Minas Gerais representa bem o que ocorre no resto do país, pode-se concluir que, no que concerne à intervenção do Estado na economia do setor agropecuário, o Brasil está na contramão das tendências atuais dos países mais desenvolvidos, nos quais, cada vez mais, esse setor é enfocado num contexto holístico, envolvendo, de forma integrada, múltiplos objetivos e políticas de preservação do meio ambiente e das culturas autóctones, a segurança alimentar, a inclusão social e a ocupação do espaço nacional.
\end{abstract}

Palavras-chave: despesa pública, agricultura multifuncional, sustentabilidade e produtivite.

\footnotetext{
${ }^{1}$ Mestre em Teoria Econômica pelo CEDEPLAR/UFMG, Doutora em Economia Aplicada pela Universidade Federal de Viçosa, Pesquisadora da Fundação João Pinheiro. Endereço: Rua Pirapetinga n. 107 apto 202 Serra, CEP: 30.220.150 - Belo Horizonte - Minas Gerais. E-mail: marbara@ superig.com.br. Fones: (31) 32871167 ou (31) 32871241.

${ }^{2}$ Mestre em Economia Rural da Universidade Federal de Viçosa, Doutor em Economia pela USP, Professor de Macroeconomia dos Programas de Mestrado e Doutorado da UFV, Condomínio Bosque do Acamari, n. 38 CEP: 36.570 .000 - Viçosa - Minas Gerais. E-mail: jmasilva@ ufv.br Fones: (31) 3899-1343 ou (31) 38913677.
}

Recebido em 01/09/2003 Aceito em 31/10/2003 


\section{Introdução}

No Brasil, em contraste com outros países em que predomina a cultura do planejamento estratégico e realista, quaisquer demonstrações de êxitos agropecuários são suficientes para despertar o tradicional ufanismo quanto à vocação agrária do país.

O crescimento da produtividade, da produção de grãos no cerrado, das exportações agrícolas e seus reflexos positivos na balança comercial têm alimentado essa euforia, favorecendo a expansão dos agronegócios de alta escala. Problemas relativos às externalidades ambientais negativas, ao desemprego e à exclusão social no campo não têm merecido a mesma atenção dos meios de comunicação e nem têm sido levados a sério nas políticas públicas para a agricultura (Alves da Silva, 2002).

Em contraste, na agenda dos países desenvolvidos torna-se cada vez mais presente o conceito de agricultura multifuncional, orgânica e familiar, com base numa análise multidimensional e criteriosa, na qual o agricultor não é enfocado apenas como produtor de alimentos ou de fibras para a indústria, mas também como um cidadão-rural, guardião da cultura e do meio ambiente.

Bodin-Rodier e Blanchet (1997, p.40) cunharam o termo produtivite para designar o conjunto de efeitos colaterais sobre o ambiente social e sobre a natureza, associados ao aumento da pressão competitiva sobre os agricultores. A idéia é que, pressionados a aumentar cada vez mais a produtividade, num mundo globalizado que requer crescente articulação com grandes tradings e firmas agroindustriais, os agricultores trabalham ativamente para o seu próprio desaparecimento. No limite, a produtivite conduz, paradoxalmente, à pauperização e à perda de identidade do homem rural. Ao buscar maximizar os resultados, a agricultura acaba, assim, participando ativamente da geração de várias formas de externalidades negativas, de naturezas sociais, sanitárias e ambientais. 
Essas questões têm despertado crescente interesse, nos últimos anos, sendo tema constante de fóruns internacionais, em razão das pressões exercidas por ambientalistas, por críticos da globalização, por combatentes e defensores dos subsídios agrícolas protecionistas que os Estados europeus e os Estados Unidos insistem em manter, sob o argumento da multifuncionalidade.

Nessa perspectiva, empreende-se, aqui, uma análise do comportamento gasto público na função agricultura em Minas Gerais, visando identificar a importância do sistema operacional da agricultura do estado e a distribuição de competências entre esse sistema e outros sistemas operacionais da administração pública que participam da distribuição da verba pública alocada na função agricultura.

Além dessa introdução, o artigo traz quatro seções. Na seção 2, destacam-se alguns pontos essenciais da metodologia adotada. Na seção 3, intitulada resultados e discussão, procede-se à comparação entre execução orçamentária do sistema operacional da agricultura e valores das despesas classificadas na função agricultura, em Minas Gerais; em seguida, é avaliado o comportamento dos gastos, por meio da metodologia funcional programática para 1985-2001, pelos seus vários desdobramentos. As conclusões são apresentadas na seção 4.

\section{Metodologia}

O levantamento de dados e informações foi estruturado num enfoque setorial e num grau de detalhamento de maior alcance do que usualmente costuma ser feito em estudos sobre gastos públicos. As tabelas básicas ${ }^{3}$ permitem partir da despesa por função (discrimina o total de gastos do governo estadual e o seu desdobramento pelas 16 funções, conforme classificação programática das despesas, dentre as quais se encontra a função 4 - agricultura). Procede-se, em seguida, ao novo desdobramento, para conhecer, especificamente, o total de gastos com os programas

${ }^{3}$ As tabelas podem ser consultadas em Baracho (2003). 
classificados na função agricultura e a participação destes no conjunto dos gastos. Desdobra-se a despesa dos programas da função agricultura em subprogramas, apresentando-se a estrutura dos programas em subprogramas, meio e fim, e a apresentação da despesa, por unidades orçamentárias da administração direta e indireta vinculadas à execução dos programas da função agricultura; despesa da Administração Direta; e, por último, o desdobramento dos programas por projeto e atividade. Para as entidades da administração indireta procede-se ao desdobramento da despesa da função agricultura por unidade orçamentária, programas, subprogramas, projetos e atividades.

Pela Portaria 42, de 14 de abril de 1999, a função Agricultura passou a ter sete subfunções (601-Promoção da Produção Vegetal, 602-Promoção da Produção Animal, 603-Defesa Sanitária Vegetal, 604-Defesa Sanitária Animal, 605-Abastecimento, 606-Extensão Rural e 607-Irrigação), classificação não prevista na Lei n.4320. Além disso, o programa Organização Agrária foi transformado em função, com duas subfunções, 631 - Reforma Agrária e 632 - Colonização. Portanto, os gastos públicos em agricultura passaram, a partir daí, a ser contabilizados não mais em uma, mas em duas funções: Agricultura e Organização Agrária. Ainda não está muito claro como essa nova sistemática poderá afetar a continuidade das estatísticas dos gastos. O que se verifica é que a passagem de denominação de alguns programas para subfunções poderá interromper séries de informações disponíveis até 2000, ou, alternativamente, a manutenção dessas séries implica utilizar e procurar compatibilizar categorias distintas da funcional programática. Assim, em vez de caminhar para maior transparência, o sistema brasileiro de orçamento público parece orientar-se em direção contrária.

Aqui, adotou-se o tratamento de natureza institucional e funcional pela classificação funcional programática. Entretanto, considerando-se que não apenas a administração pública estadual e, mais especificamente, o sistema operacional de agricultura do estado executem gastos orçamentários na função agricultura em Minas Gerais, a amplitude dos gastos públicos é maior, pois compreende outras esferas da administração pública, como a federal e as prefeituras municipais. É importante ampliar 
essas estimativas para a inclusão dessas despesas cobertas por recursos orçamentários e, ao mesmo tempo, adotar procedimentos para evitar a dupla contagem de valores.

Para estimativas mais abrangentes, relativas ao volume de gastos públicos em agricultura realizados em Minas Gerais, é importante a inclusão dos recursos federais e municipais aplicados, além dos valores da esfera estadual, bem como o levantamento de convênios internacionais firmados entre o governo federal e agências internacionais que viabilizam a captação de recursos externos para aplicação em projetos e atividades agrícolas. $^{4}$

\section{Resultados e discussão}

A despesa pública da administração estadual em Minas Gerais passou de R \$ 10,5 bilhões, em 1985, para R \$ 14,4 bilhões, em 2001, a preços constantes da média de 2001, com uma taxa de crescimento real de 2,1\%, em média, ao ano, no período de 1985 a 2001.

Os dados da função Agricultura mostram que as despesas nela classificadas atingiram R $\$ 270,0$ milhões em 1985, passando para $\mathrm{R} \$ 192,6$ milhões, em 1994, para R\$118,0 milhões, em 2001, a preços constantes de 2001, com queda real de $-5,0 \%$, em média, ao ano, no período de 1985 a 2001. Essa taxa, além de negativa, foi inferior à média da execução estadual, que alcançou 2,1\%, em média, ao ano, no período de 1985 a 2001, o que indica que a agricultura vem perdendo posição tanto em volume absoluto das despesas como em participação relativa.

As despesas na função Agricultura ocuparam a $11^{a}$ posição no ranking orçamentário de Minas Gerais, com 1,26\% do total da despesa, no período de 1985 a 2001. Em posição inferior à agricultura estão apenas as funções Energia e Recursos Minerais (0,48\%), Habitação e Urbanismo $(0,35 \%)$, Trabalho $(0,21 \%)$ e Comunicações $(0,09 \%)$.

${ }^{4}$ Outros ensaios nessa linha, que buscam proceder ao levantamento considerando-se a formação de redes, estão disponíveis em Baracho (2003). 
A evolução das despesas realizadas no período de 1985 a 2001, agregadas por funções Administrativas (1 - Legislativa, 2 - Judiciária e 3 Administração e Planejamento), Produtivas (4 - Agricultura e 11 - Indústria, Comércio e Serviços), Infra-estrutura (5 - Comunicações, 9 Energia e Recursos Minerais e 16 - Transportes), e Sociais 1 (6 Defesa Nacional e Segurança Pública, 8 - Educação e Cultura e 13 Saúde e Saneamento), Sociais 2 (14 - Assistência e Previdência e 15 Trabalho), comparativamente à função 04 - Agricultura, é apresentada nos gráficos 1 e 2 .

Gráfico 1 - Evolução real das despesas por funções agregadas em administrativas, produtivas, infra-estrutura e agricultura, Minas Gerais - 1985-2001 (índice de crescimento real (\%) base $1985=100$ )

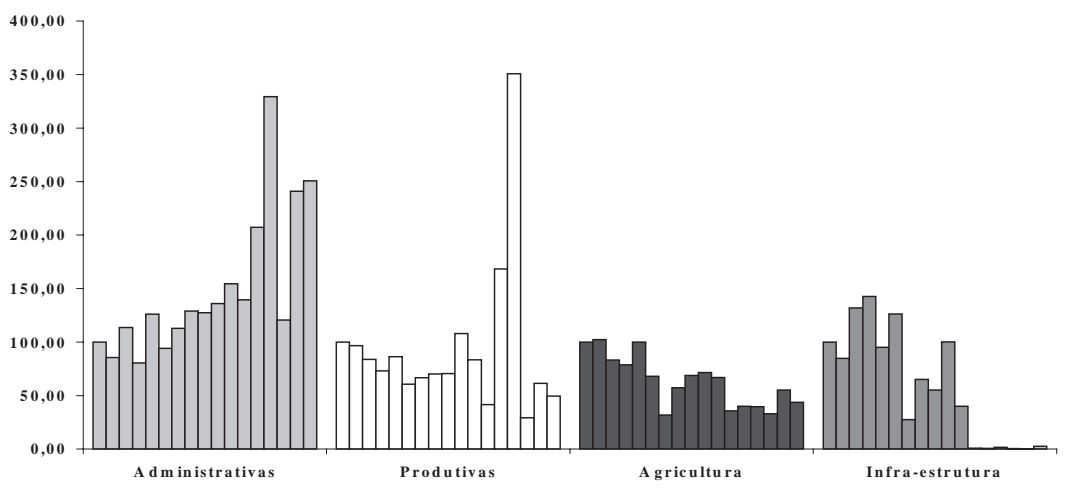

Anos 1985-2001

Fonte: Dados Básicos: Secretaria de Estado da Fazenda (SEF), Contadoria Geral do Estado (CGE). BALANÇOS GERAIS, Belo Horizonte, Minas Gerais, 1985 a 2001. Elaboração: Baracho (2003).

${ }^{1}$ Corrigidos pelo IGP (DI). 
Gráfico 2 - Evolução real das despesas por funções agregadas em sociais 1 e sociais 2 e agricultura, Minas Gerais - 1985-2001 (índice de crescimento real $(\%)$ base $1985=100)$

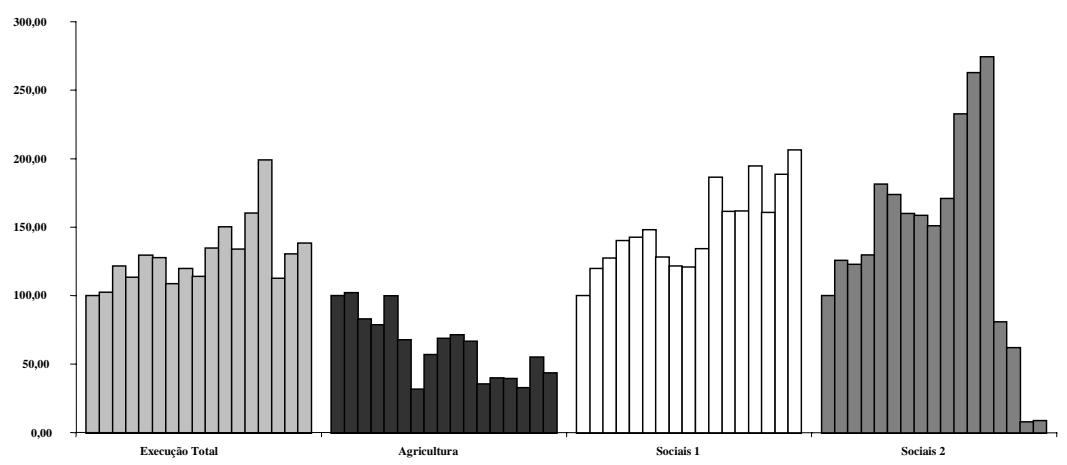

Fonte: Dados Básicos: Secretaria de Estado da Fazenda (SEF), Contadoria Geral do Estado (CGE). BALANÇOS GERAIS, Belo Horizonte, Minas Gerais, 1985 a 2001. Elaboração: Baracho (2003).

${ }^{1}$ Corrigidos pelo IGP (DI).

A execução total apresentou tendência de expansão no período de 1985 a 2001, embora os valores oscilassem de um exercício para outro, com um desvio-padrão médio de $\mathrm{R} \$ 1,76$ bilhão, a preços constantes da média de 2001.

As funções classificadas como administrativas (Administração e Planejamento, Legislativa e Judiciária) apresentaram tendência expansiva e definiram o comportamento da execução total. $\mathrm{O}$ valor de pico ocorreu em 1998, sendo explicado pela privatização no estado, que resultou em maior disponibilidade de recursos. Esses recursos de alienação de bens foram despendidos em algumas funções, principalmente na função Administração e Planejamento, para pagamento de dívidas (gráf. 1).

O pico, também em 1998, no grupo de funções produtivas não decorreu do comportamento da função agricultura, mas se explicou pela expansão de programas governamentais de apoio ao setor industrial do Estado. A privatização em Minas Gerais não carreou recursos para a função agricultura, cujas despesas apresentaram tendência de queda, e as funções 
sociais também não receberam esses recursos. Essas funções apresentaram estabilidade e expansão, no início da série, e queda em alguns subperíodos, no final da série em estudo (gráf. 2).

As unidades executoras de despesas, classificadas na função Agricultura, compreendem as Secretarias de Agricultura, em toda a série; de Abastecimento, no período 1985/87; de Obras, em 1989/90. Juntas, essas três entidades da Administração Direta estadual responderam por $\mathrm{R} \$ 432,31$ milhões, a preços constantes de 2001, ou 14,9\% da execução orçamentária total no valor de R \$2,90 bilhões, relativa à função agricultura, no período de 1985 a 2001 (Tab.1).

A maior parcela dessa despesa, de $\mathrm{R} \$ 2,90$, é classificada em Encargos Gerais, sendo realizada mediante repasses do Tesouro Estadual às empresas agrícolas subvencionadas e a outras empresas, representando $52,2 \%$ do total ou R \$ 1,51 bilhão, a preços constantes da média de 2001, no período de 1985 a 2001. Já as transferências às fundações e autarquias, que executam despesas classificadas na função Agricultura, receberam, no período de 1985 a 2001, recursos transferidos por meio de Encargos Gerais do Estado, num montante de $\mathrm{R} \$ 495,96$ milhões, a preços constantes da média de 2001, cerca de $17,1 \%$ do valor total transferido para a administração indireta estadual mediante Encargos Gerais. Programas diversos e fundos ocupam as últimas posições relativas, com percentuais de $11,9 \%$ e 3,9\% do total, equivalentes a $\mathrm{R} \$ 343,36$ milhões e $\mathrm{R} \$ 113,81$ milhões, a preços constantes da média de 2001. Vale lembrar que, em geral, os programas diversos foram executados mediante utilização de recursos internacionais (Tab.1). 
Maria Amarante Pastor Baracho \& José Maria Alves da Silva

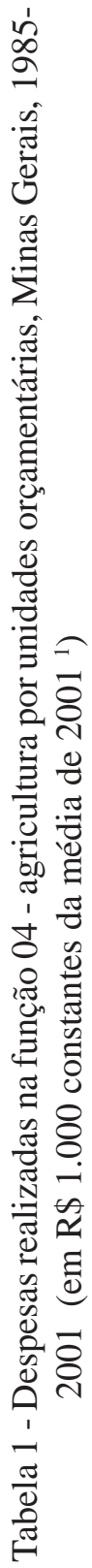

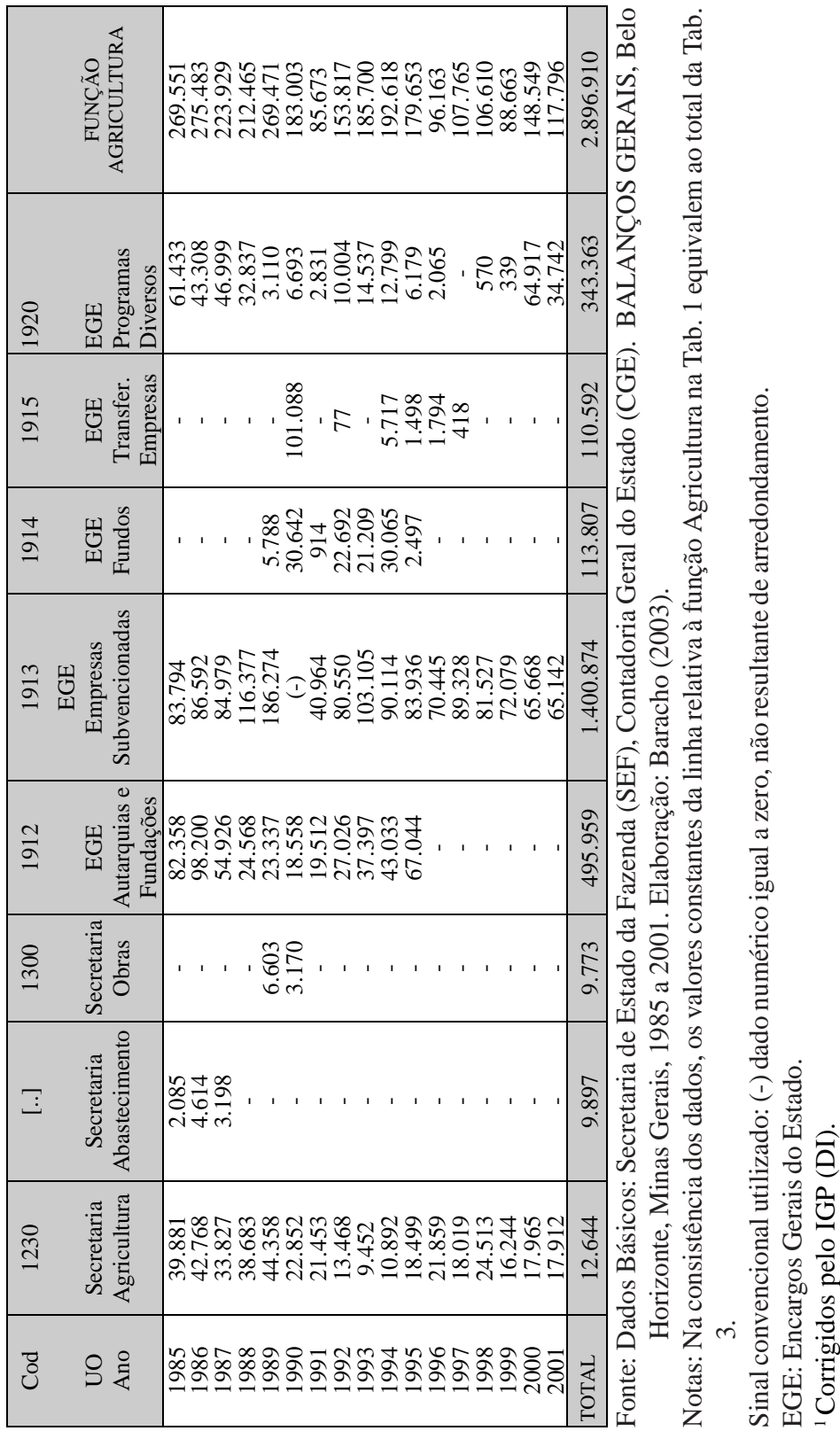


As despesas classificadas na função agricultura atingiram, de 1995 a 2001, respectivamente, $\mathrm{R} \$ 179,65$ milhões, $\mathrm{R} \$ 96,16$ milhões, $\mathrm{R} \$ 107,75$ milhões, $\mathrm{R}$ \$ 106,61 milhões, $\mathrm{R}$ \$ 88,66 milhões, R \$ 148,55 milhões e R \$ 117,79 milhões, a preços constantes de 2001. Já os valores executados pelo Sistema Operacional da Agricultura perfizeram, respectivamente, $\mathrm{R} \$ 75,10$ milhões, $\mathrm{R} \$ 89,40$ milhões, $\mathrm{R} \$ 84,80$ milhões, $\mathrm{R}$ \$ 95,30 milhões, $\mathrm{R} \$$ 68,50 milhões, $\mathrm{R} \$ 66,80$ milhões e $\mathrm{R} \$ 70,40$ milhões, a preços constantes da média de 2001.

Assim, verifica-se que as despesas executadas pelo sistema operacional da agricultura foram sensivelmente inferiores às despesas na função agricultura, a cada exercício, o que indica que órgãos e entidades de outros sistemas operacionais, como meio ambiente, planejamento, ciência e tecnologia, saneamento básico e indústria e comércio, também classificaram despesas na função agricultura. Essa diferença entre despesa na função agricultura e despesas no setor agrícola, executada pelo sistema operacional da agricultura, atingiu um montante acumulado, no período de 1995 a 2001,de R \$294,90 milhões, a preços constantes de 2001. Esses números indicam que o sistema operacional da agricultura de Minas Gerais vem perdendo competência institucional para executar projetos e atividades que ainda estão classificados na função agricultura.

Ao considerar outros desdobramentos das despesas na função agricultura, verifica-se que despesas executadas anualmente, no período 19852001, pelos principais programas da função Agricultura, figuram na Tabela 2 .

Os valores, acumulados no período 1985-2001, das despesas de cada um dos programas da função agricultura e suas participações relativas nas despesas totais da função agricultura são apresentadas no gráfico 3 . 


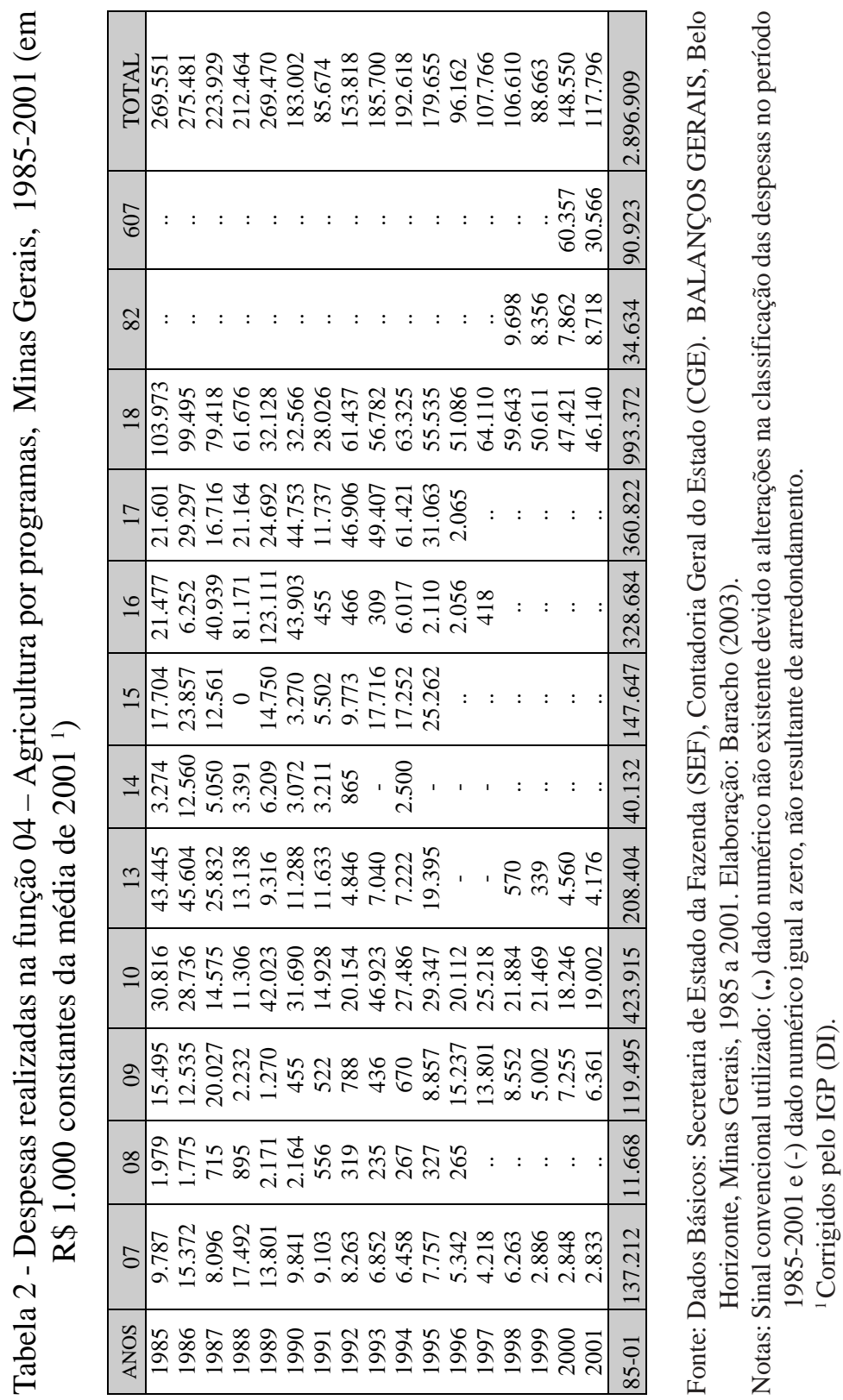


Os programas pelos respectivos códigos são: (07) Administração, (08) Administração Financeira, (09) Planejamento Governamental, (10) Ciência e Tecnologia, (11) Organização Agrária, (14) Produção Vegetal, (15) Produção Animal, (16) Abastecimento, (17) Preservação de Recursos Naturais Renováveis, (18) Promoção e Extensão Rural, (82) Previdência e (607) Irrigação.

O maior volume de despesas realizadas encontra-se no programa Promoção e Extensão Rural, que deteve 34,3\% do total, em média, ao ano, no período de 1985 a 2001, registrando quedas no início da série e relativa estabilidade a partir de 1992. Os valores anuais das despesas desse programa oscilaram entre o menor valor de $\mathrm{R} \$ 28,03$ milhões, de 1991, e R\$ 103,97 milhões, o maior valor registrado em 1985. De 1992 a 2001, quando a variabilidade foi menor, verifica-se relativa estabilidade, visto que os limites ficaram entre R\$ 64,1 milhões, em 1992, e R \$ 46,14 milhões, em 2001.

A segunda posição relativa foi ocupada pelo programa Ciência e Tecnologia, com 14,6\% em média, ao ano, do total de gastos em agricultura realizados pela administração pública estadual em Minas Gerais, no período de 1985 a 2001. Esse programa também apresentou estabilidade no período, mas com tendência de queda no final da série histórica. 
Gráfico 3 - Despesas realizadas por principais programas - Minas Gerais -1985 a 2001 (valores acumulados e participação relativa) (em $\mathrm{R}$ \$ milhões constantes da média de 2001 e em percentual)

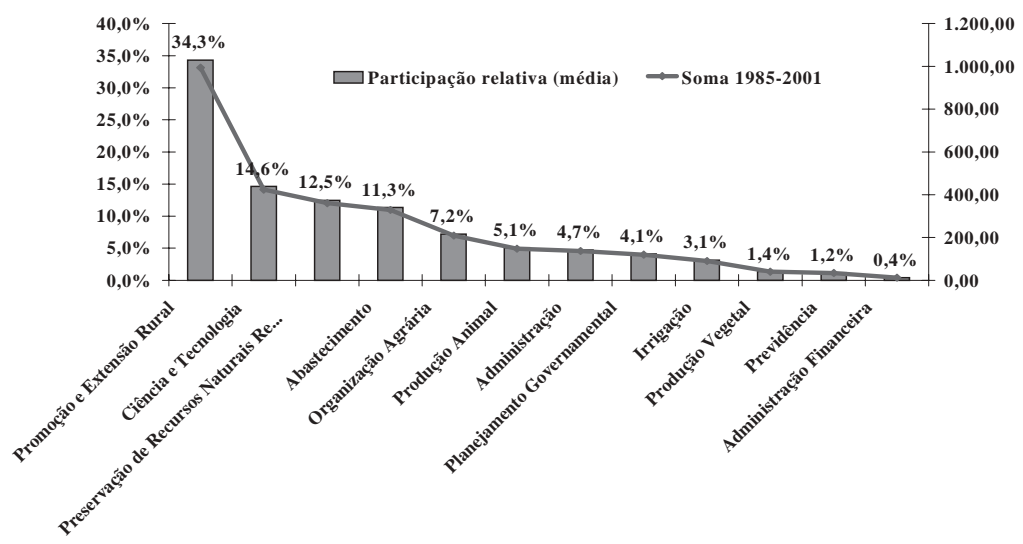

Fonte: Dados Básicos: Secretaria de Estado da Fazenda (SEF), Contadoria Geral do Estado (CGE). BALANÇOS GERAIS. Belo Horizonte. Elaboração: Baracho (2003).

Nota: ${ }^{1}$ Corrigidos pelo IGP (DI).

O Programa Preservação de Recursos Naturais Renováveis ocupou a terceira posição, com 12,6\% em média, ao ano, no período de 1985 a 2001, do total das despesas na função agricultura. Nesse programa, as despesas acumuladas, a preços constantes da média de 2001, atingiram R\$ 360,82 milhões, de 1985 a 2001. As despesas classificadas nesse programa apresentaram oscilações significativas, de 1985 a 1995, de um valor mínimo de $\mathrm{R}$ \$11,74 milhões, em 1991, a um valor máximo de $\mathrm{R}$ \$ 61,42 milhões, em 1994, a preços constantes da média de 2001, com valores nulos no período de 1997 a 2001. Os valores de 1994-1996 resultaram da importância dos financiamentos externos na cobertura das despesas do Pró-floresta. Os valores nulos, a partir de 1997, resultaram da transferência do Instituto Estadual de Florestas para a Secretaria de Estado do Meio Ambiente, quando as despesas desse Instituto passaram a ser classificadas em outras funções como Saúde, Saneamento e Meio 
Ambiente, e não mais na função Agricultura.

Os gastos classificados nos programas Abastecimento e Organização Agrária ficaram nas duas posições seguintes, com, respectivamente, 11,4\% e 7,2 \% do total. Os gastos em Organização Agrária, classificados na função Agricultura, reduziram-se, significativamente, no final do período, dada a criação do Instituto de Terras, sob a supervisão da Secretaria de Estado do Planejamento e Coordenação Geral. As despesas desse Instituto, embora sejam em Agricultura, são classificadas em outra função. O processo de desativação da Ruralminas, sob supervisão da Secretaria de Estado da Agricultura, e a transferência de suas atribuições e competências no que tange à Organização Agrária encontram-se inconclusos. Permanecem duas entidades distintas com atribuições similares e concorrentes e com despesas classificadas em distintas funções.

Os programas Produção Animal, Irrigação e Produção Vegetal detiveram, respectivamente, $5,1 \%, 3,1 \%$ e $1,4 \%$ do total das despesas em agricultura, em média, ao ano, no período de 1985 a 2001. Além dos programas já mencionados, outros que figuram no gráfico 3 podem ser considerados programas-meio, cujas participações, somadas, perfizeram 10,5\% em média, ao ano, do total das despesas na função agricultura em Minas Gerais, no período de 1985 a 2001.

A partir dos valores acumulados dos programas-meio e dos programasfim, verifica-se que, para $\mathrm{R} \$ 1,00$ gasto em programas-fim, foram despendidos $\mathrm{R} \$ 0,33$ em programas-meio, ou, ainda, para $\mathrm{R} \$ 1,00$ despendido em programas-meio, foram despendidos $\mathrm{R} \$ 2,97$ em programas-fim. Isso equivale dizer que, dos $\mathrm{R} \$ 2,90$ bilhões em valores constantes de 2001, gastos na função Agricultura de Minas Gerais, de 1985 a 2001, em Minas Gerais, R\$2,17 bilhões estavam aplicados em programas-fins e R\$ 726, 92 milhões, em programas-meio.

As despesas com agricultura são executadas pelas fundações, autarquias e empresas que compõem o sistema operacional da agricultura, supervisionado pela Secretaria de Agricultura, e também por outras instituições que estão fora desse sistema. No levantamento dos dados, considerou- 
se toda a despesa realizada dentro e fora do sistema operacional da Agricultura.

As mudanças institucionais no sistema operacional, no período de 1985 a 2001, refletiram-se na execução orçamentária do Estado, contabilizada em todos os desdobramentos da função Agricultura. Nos dados dos subprogramas, em cada um dos exercícios financeiros e por projetos e atividades pelas várias unidades orçamentárias, verifica-se que muitos projetos e atividades não mais se vinculam ou estão sob a competência de órgãos e entidades supervisionadas pela Secretaria de Estado da Agricultura.

No que tange ao desdobramento por subprogramas, excetuando-se as mudanças de denominação dos subprogramas como Pesquisa Fundamental (54) e Pesquisa Aplicada (55) ou Reforma Agrária (66) e Colonização (67), que se substituem no período de 1985 a 1999, muitos dos outros subprogramas passaram a ser de competência de outros sistemas operacionais, como Reflorestamento, Conservação de Solos e Preservação de Recursos Naturais Renováveis.

Dois grandes subprogramas da Agricultura - Extensão Rural e Pesquisa Fundamental/Pesquisa Aplicada, permaneceram com despesas em toda a série 1985 a 1999. Enquanto no primeiro foram despendidos os valores acumulados de $\mathrm{R} \$ 680,18$ milhões, a preços constantes da média de 2001, no segundo, o montante total alcançou R \$ 401,06 milhões. Como agravante, tem-se que, enquanto as despesas em Extensão Rural cresceram 7,4\% em média, ao ano, no período de 1985 a 1999, as despesas com Pesquisas Fundamentais e Aplicadas para a área agrícola, incluindo Testes e Análises, decresceram - 0,5\%, em termos reais, em média ao ano, no mesmo período. Essa constatação pode indicar também que, se esses gastos estão sendo efetuados por outros sistemas operacionais do estado, mediante, por exemplo, a atuação da Fundação de Amparo à Pesquisa de Minas Gerais - Fapemig, ou pelas Universidades Federais que atuam no estado, mediante apoio financeiro da Fapemig, tem ocorrido relativo deslocamento da função de pesquisa aplicada ao sistema operacional da agricultura. É importante, nesse caso, assegurar que pes- 
quisas nessa linha atendam, especificamente, às demandas do sistema operacional da agricultura do Estado, com vistas em dar suporte às suas atividades de extensão rural e promoção agrária.

Os principais subprogramas-meio da função Agricultura, como Supervisão e Coordenação Superior e Administração Geral, no período de 1995 a 1999, registraram montantes acumulados de despesas de, respectivamente, R \$ 27,54 milhões e R \$ 98,99 milhões, a preços constantes da média de 2001. Somando-se a esses montantes o restante das despesas de outros subprogramas-meio, como Planejamento e Orçamentação, Controle Interno, Informática, a cifra acumulada foi de R \$ 279,56 milhões em todo o período considerado. A evolução das despesas dos subprogramas também apresentou tendência de queda, com taxas médias anuais estimadas em - 4,76\% e - 6,26\%, respectivamente, para os programas Supervisão e Coordenação Superior e Administração Geral. Esses números também evidenciam a perda de importância relativa do sistema operacional da agricultura, em face a outros sistemas operacionais no Estado.

A estrutura mais "enxuta" dos novos programas-fins e das Obrigações Especiais do sistema operacional da agricultura, a partir da Portaria 42, de 14 de abril de 1999, corrobora a constatação anterior. Verifica-se que, nos exercícios de 2000 e 2001, o sistema operacional da Agricultura contabilizou despesas apenas com Programas de Assentamento e de Desenvolvimento Regional, além das despesas com áreas-meio. Nesses últimos números não estão incluídas as despesas feitas pelas empresas supervisionadas pela Secretaria de Estado da Agricultura. Portanto, podese perceber que as despesas com Extensão Rural continuam sendo efetuadas pela Emater, mediante parcela de recursos transferidos pelo Tesouro Estadual e contabilizadas na função Agricultura.

Os desdobramentos, em menores níveis de agregação, da despesa da função Agricultura, por subprogramas e por projetos e atividades, permitiram atingir o levantamento por programas e por função e, a partir daí, tecer considerações sobre o comportamento desses e também identificar, mais detalhadamente, a despesa pela sua finalidade e pela unidade 
executora. ${ }^{5}$

As assertivas explicitadas de que ações nas áreas de reflorestamento, abastecimento e armazenamento, preservação de recursos naturais renováveis, recursos hídricos e pesquisa aplicada ficavam anteriormente sob competência de outros sistemas operacionais do estado ou por outras esferas da administração pública e eram executadas por estes, e não mais pelo sistema operacional da agricultura em Minas Gerais, também são corroboradas por esses dados de subprogramas, projetos e atividades.

Na última etapa do levantamento por projetos e atividades, além da evolução e da composição dos dispêndios, verifica-se o montante de recursos anualmente transferidos para entidades da administração indireta estadual e para empresas públicas estaduais que atuam na área da agricultura. A Ceasa e a Casemg receberam recursos de 1994 a 1997, sendo em 1998 federalizadas, enquanto a Emater e a Epamig receberam recursos transferidos em todo o período de 1985 a 2001.

No levantamento por projetos e atividades, verifica-se que a execução dos órgãos e entidades da administração indireta foi superior aos recursos transferidos pelo tesouro estadual. Exemplificando, em 1995, o Instituto Estadual de Florestas recebeu R 22,39 milhões de recursos transferidos do Tesouro Estadual e realizou despesas no montante total de R $\$$ 34,74 milhões, o que indica um montante de recursos de $\mathrm{R} \$ 12,35 \mathrm{mi}$ lhões procedentes de outras fontes, como recursos internacionais do Prófloresta e recursos resultantes de parcerias com o governo federal, executivos municipais e iniciativa privada. Verifica-se que, a partir de 1998, o Instituto Estadual de Florestal, nessa ocasião sob supervisão da Secretaria Estadual do Meio Ambiente, passou a contabilizar suas despesas na função 12 - Saúde e Saneamento e, posteriormente, após a Portaria 42, de 14 de abril de 1999, na função 18 - Gestão Ambiental, mantendo

\footnotetext{
${ }^{5}$ A consistência é significativa, pois em todos os desdobramentos por função, programa, subprograma, projeto e atividade verifica-se que os valores de despesas em agricultura, em quaisquer desses níveis, são sempre iguais. Essa consistência, possibilitada pela metodologia desenvolvida, auxiliou a conferência do levantamento dos dados em suas várias etapas.
} 
no período de 1998 a 2001 as mesmas atividades e projetos do período de 1994 a 1997, tanto nas áreas-meio quanto nas áreas-fins. Além das atividades-meio, como Direção Organizacional Interna e Serviços de Apoio Administrativo e Financeiro, esse Instituto teve despesas, de modo descontínuo, com vários programas de proteção ambiental da flora e da fauna, mas as atividades e os projetos de reflorestamento tiveram continuidade em suas despesas, em todo o período. As despesas com Direção Organizacional Interna e Reflorestamento tiveram a mesma tendência de comportamento no período de 1990 a 2001, e os períodos de picos que se referem à entrada de recursos do Pro-floresta são observados em ambos (Tab.3) 


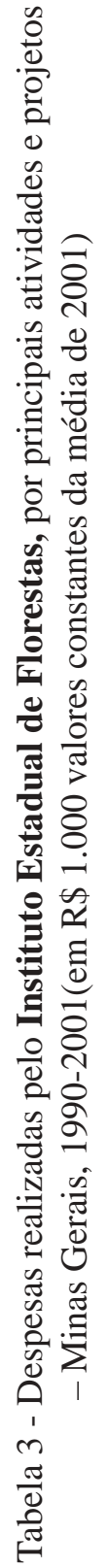

\begin{tabular}{|c|c|c|}
\hline 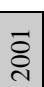 & 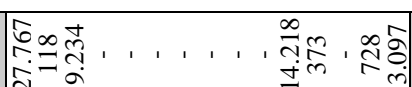 & \begin{tabular}{|c|c|} 
\\
$n$ \\
$n$ \\
$n$ \\
$n$
\end{tabular} \\
\hline §ి & 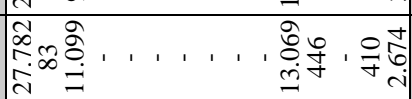 & $\left|\begin{array}{l}n \\
n \\
n \\
n \\
n \\
n\end{array}\right|$ \\
\hline & 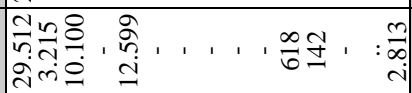 & \begin{tabular}{|l|}
$\overline{8}$ \\
$\dot{0}$ \\
$i$ \\
\end{tabular} \\
\hline$\stackrel{\infty}{\curvearrowright}$ & 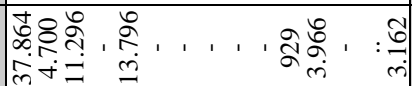 & 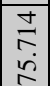 \\
\hline$\hat{2}$ & 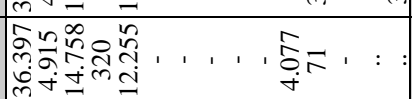 & 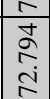 \\
\hline ๖ & 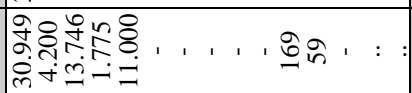 & \begin{tabular}{|l|}
$\infty$ \\
$\infty$ \\
\\
\\
\end{tabular} \\
\hline 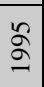 & 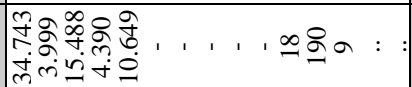 & \begin{tabular}{|c|} 
\\
$\infty$ \\
$\dot{0}$ \\
$\dot{0}$ \\
\end{tabular} \\
\hline$\stackrel{+}{2}$ & 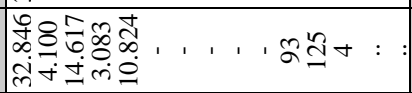 & $\begin{array}{c}0 \\
\hat{b} \\
\dot{b} \\
\vdots\end{array}$ \\
\hline$\check{\Omega}$ & 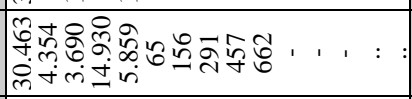 & \begin{tabular}{|l|} 
\\
\\
$\delta$ \\
$\delta$ \\
$\delta$ \\
\end{tabular} \\
\hline ऽ̆ & 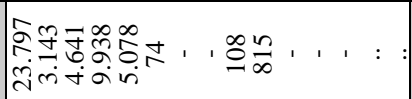 & $\mid \begin{array}{l}n \\
n \\
i \\
r\end{array}$ \\
\hline $\bar{\sigma}$ & 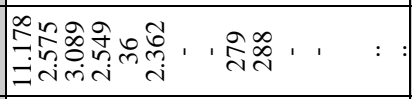 & 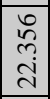 \\
\hline$\stackrel{2}{2}$ & 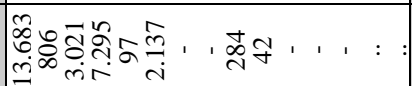 & 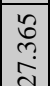 \\
\hline 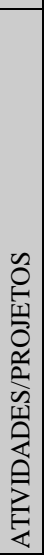 & 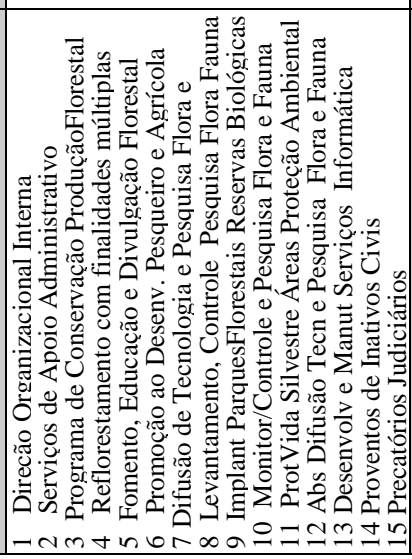 & \\
\hline
\end{tabular}


Na Tabela 4 verifica-se que os dados da Ruralminas refletem os constrangimentos institucionais e as dificuldades operacionais que essa Fundação vêm enfrentando, em vários focos da análise, como sensíveis oscilações das despesas em atividades-meio no período 1990-2001, atuação descontínua em vários projetos e atividades-fins nas áreas de irrigação e drenagem, reforma agrária, apoio à produção e engenharia de motomecanização. 


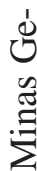

$\frac{1}{0}$

0

曾

음

ส

.

ఏ

힘

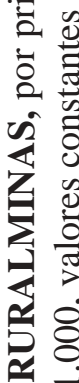

$\frac{\pi}{0} \sim$

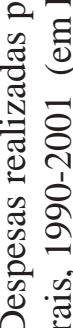

$\frac{1}{4}$
$\frac{\pi}{0}$
$\frac{\pi}{0}$

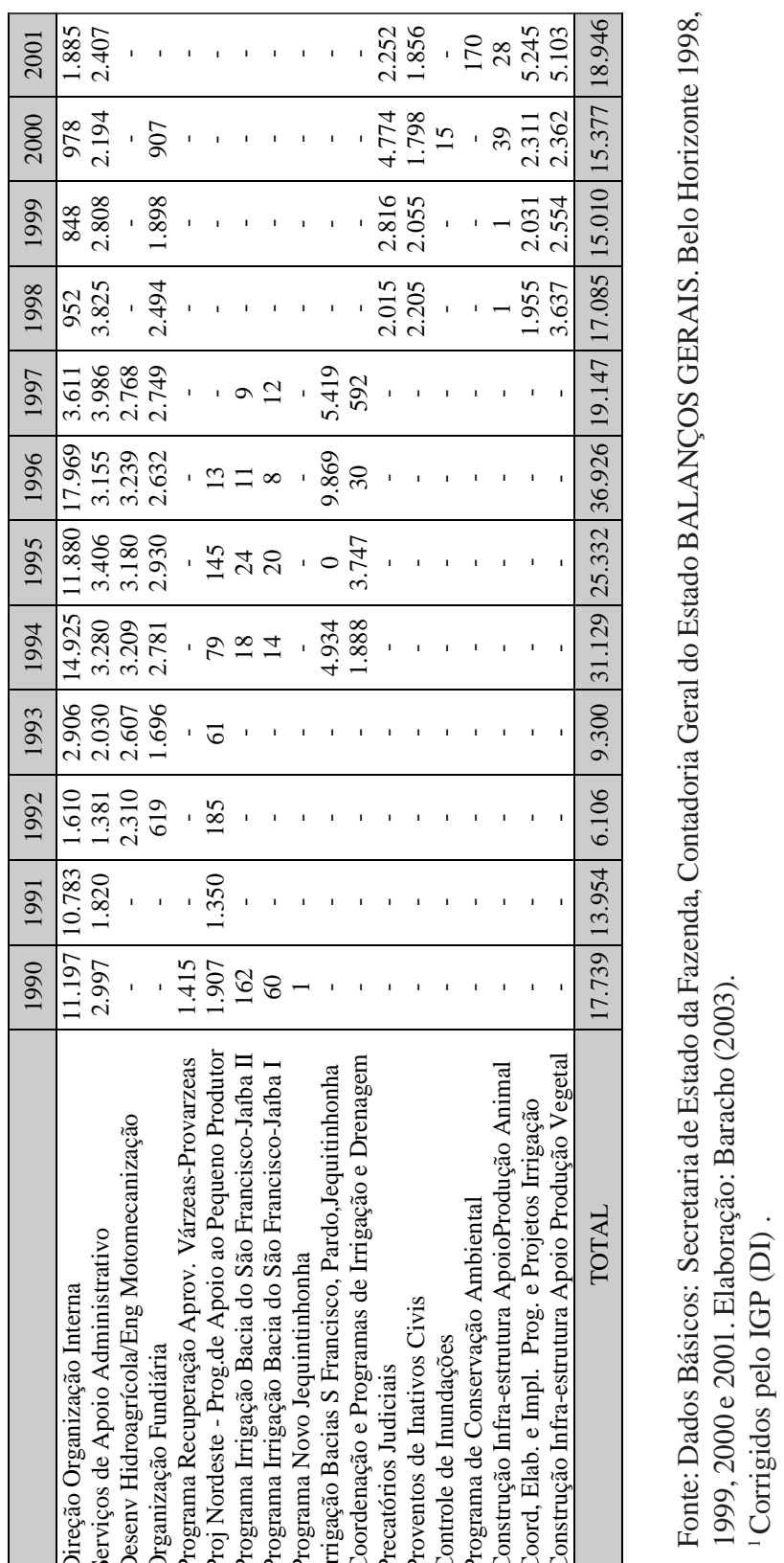


Os períodos de picos nas despesas, de 1994 a 1996, refletem maior aplicação dos recursos externos nos projetos de irrigação Jaiba I e Jaíba II. Verificam-se estabilidade da atividade-meio (Serviços de Apoio Administrativo), reduzida importância relativa do Programa de Apoio ao Pequeno Produtor (PAPP), em termos de montante de recursos mobilizados, e tendência de queda nas despesas com ação fundiária.

A partir de 2000, a Ruralminas deixou de atuar nos setores de colonização e titulação de terras, para concentrar-se na elaboração, coordenação e execução de planos, programas e projetos de desenvolvimento rural e na implementação de projetos de irrigação, saneamento e motomecanização, assim como na implantação de perímetros públicos irrigados, atuando, na maioria das vezes, em parceria com as prefeituras.
A partir de 1992, o Instituto Estadual de Saúde Animal (IESA) foi substituído pelo Instituto Mineiro de Agropecuária (IMA), que passou a executar também algumas ações que, anteriormente à sua criação, eram de competência da Secretaria de Estado da Agricultura (Tab.5) 


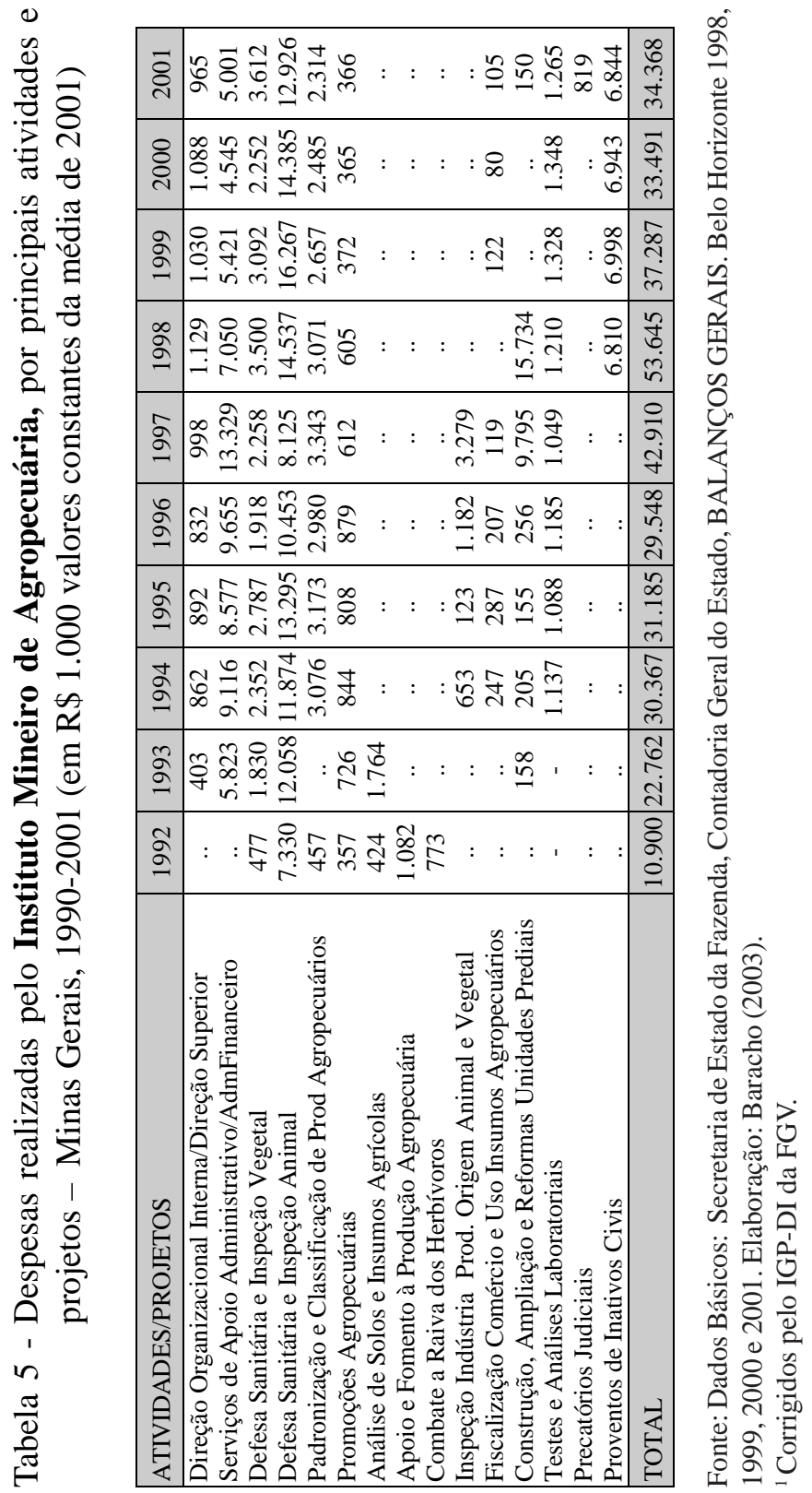


Verifica-se que esse Instituto apresentou, no período de 1992 a 2001, expansão das despesas em atividades-meio, como Direção Organizacional Interna e Serviços de Apoio Administrativo e Financeiro. Quanto aos projetos e atividades-fins, verifica-se que alguns apresentaram tendência expansiva no período, como Defesa Sanitária e Inspeção Animal; outros, relativa estabilidade, como Defesa Sanitária e Inspeção Vegetal, Testes e Análises Laboratoriais e Padronização e Classificação de Produtos Agropecuários; enquanto alguns, valores de pico em determinados exercícios, como Construção e Ampliação de Unidades Prediais em 1997 e 1998, Promoções Agropecuárias de 1993 a 1996 e Precatórios Judiciais apenas em 2001. O programa proventos a inativos, que apresentou despesas no período de 1998 a 2001, refletiu mudanças nas classificações orçamentárias, pois, anteriormente à Portaria 42, eram classificadas em uma única função - Assistência e Previdência.

\section{Conclusões}

Os dados relativos à execução das despesas em agricultura no período de 1985 a 2001, em Minas Gerais, indicam que a orientação das políticas agrícolas no Brasil não se coaduna com a nova abordagem multifuncional da agricultura.

Constatou-se que, além do sistema operacional da agricultura, outros sistemas operacionais da administração pública estadual têm despesas com a mesma função, em decorrência de competências comuns e mal definidas, surgimento de órgãos e entidades, como resultado muito mais de condicionantes políticos do que de adequada evolução da ação setorial, com foco na ação-fim do estado, na eficiência e na eficácia da atuação do setor público. Em vez de multifuncionalidade, verificam-se, de fato, a fragmentação das ações e a pulverização do recurso público.

Gerenciar a área da agricultura deveria ser uma das atribuições principais da administração pública, enquanto outras áreas afins, que são atribuições novas, deveriam estar subordinadas ao sistema operacional da 
agricultura, quando com ele se relacionarem. Na prática, percebe-se que tem ocorrido o contrário.

O fortalecimento do sistema operacional da agricultura implica maior alocação de recursos ordinários ao setor - os conhecidos recursos da fonte zero (tesouro do estado). ${ }^{6}$ Implica, também, a existência de poucos programas atípicos na função agricultura e redução do número de programas típicos da agricultura, classificados como atípicos em outra função, o que refletiria o retorno ao sistema operacional da agricultura de entidades supervisionadas por outros sistemas operacionais. Essas entidades que anteriormente, quando da sua criação, por exemplo, pertenciam ao sistema operacional da Agricultura, poderiam, novamente, fortalecer a estrutura institucional do setor agrícola. Na prática, o que vem ocorrendo é que uma mesma atribuição e competência se pulveriza em diversos órgãos e entidades. Vale frisar que, mais recentemente, esse equívoco adquiriu, em Minas Gerais, uma direção também espacial, em face das recém-criadas secretarias regionais de desenvolvimento, cujos impactos no orçamento da área institucional voltada para a agricultura mineira possivelmente serão desfavoráveis.

O esvaziamento da função agricultura em Minas Gerais, tal como indicado pela pulverização do gasto alocado nesta, está na direção oposta das novas abordagens multifuncionais, na medida em que implica um tratamento mais reducionista do sistema operacional da agricultura, ou seja, mais concentrado nas atividades produtivas de alimentos e matérias-primas, legando-se a outros órgãos da administração pública o exercício descoordenado de atividades que deveriam estar relacionadas com o bem-estar das comunidades rurais, harmonização da produção agríco-

\footnotetext{
${ }^{6}$ Pela classificação constante do Manual do Orçamento divulgado no site da Secretaria de Estado do Planejamento e Coordenação Geral, tem-se que recursos ordinários são recursos do Tesouro que compreendem: Recursos Ordinários Livres, para os quais não existe destinação específica, sendo passíveis de livre programação, e Recursos Ordinários Vinculados, provenientes de 1\% da Receita Corrente ordinária do Estado, destinados à FAPEMIG, para sua manutenção, bem como para financiamento de Projetos de Pesquisa em atendimento aos dispostos na Emenda Constitucional $n^{\circ}$ 17, que dá nova redação ao artigo 212, da Constituição Estadual, enquanto Recursos de Outras fontes compreendem outras classificações, como Taxas, Transferências Intra e Intergovernamentais, Outros Recursos diretamente arrecadados, Convênios, Acordos e Ajustes, etc, que, em geral, entram na Conta Única do Estado, com algumas exceções.
} 
la com o meio ambiente e com a saúde humana, inclusão social e outros objetivos pertinentes a um grande plano de desenvolvimento rural integrado.

Para estar de acordo com a nova abordagem multifuncional, o sistema operacional da agricultura deveria recuperar atribuições e competências que, no tempo, foram repassadas para outras áreas afins, como meio ambiente, energia e recursos minerais, tecnologia, turismo, coordenação regional, desenvolvimento agrário, dentre outras.

\section{Referências bibliográficas}

ALVES DA SILVA, José Maria; O neo-ufanismo agrícola. Folha de São Paulo, 20/5/2002. DER. UFV, Viçosa, 1998.

BARACHO, Maria Amarante Pastor Baracho. Gastos Governamentais em Agricultura no Brasil e em Minas Gerais, Tese de doutoramento, Viçosa, Minas Gerais, 2003.

BODIN-RODIER, Dominique e BLANCHET, Jacques, A estratégia agro-alimentar: os desafios do século XXI. Lisboa. Editora do Instituto Piaget, 1997, tradução do original em francês por Pedro Fillipe Henriques.

BOURGEOIS, Lucien, Políticas Agrícolas, Lisboa, Editora Piaget 1993, Tradução do original em francês por Ana Maria Novais. 